\title{
Decisions on disclosure to third parties made at MAPP meetings: opinions and practice
}

\author{
Catherine Penny, ${ }^{1}$ Jackie Craissati $^{2}$
}

The Psychiatrist (2012), 36, 379-385, doi: 10.1192/pb.bp.112.038786

${ }^{1}$ South London and Maudsley NHS Foundation Trust, UK, and Institute of Psychiatry, King's College London, UK ${ }^{2}$ Oxleas NHS Foundation Trust, UK

Correspondence to Catherine Penny (cpenny@nhs.net)

First received 30 Jan 2012, accepted 12 Mar 2012

\begin{abstract}
Aims and method We investigated how decisions regarding disclosure of an offender's history to a third party without the offender's consent are made at MultiAgency Public Protection (MAPP) meetings. Ten questionnaires were sent to a level 2 MAPP meeting in each of the 33 police and probation areas in London, with a request that the MAPP meeting administrator hand them out to up to 10 regular attendees.

Results Of 321 questionnaires handed out, 196 were returned, giving a response rate of $61.1 \%$. Seventy-six participants (37\%) had made a disclosure without a MAPP meeting discussion in the past 12 months. A total of 109 participants (55.9\%) reported that in their experience it had always been possible to reach a consensus on disclosure at MAPP meetings, but participants' responses to five hypothetical scenarios indicated a wide spread of opinions about when a disclosure should be made. Significant proportions of participants endorsed statements suggesting that people have a right to know offenders' histories.
\end{abstract}

Clinical implications Training on the evidence base, law and guidance relevant to disclosure decisions is necessary, and a governance system to monitor and improve decision-making should be considered. Advocacy for offenders may also improve practice.

Declaration of interest None.
Disclosure, as defined for the purposes of this study, is the sharing with a third party of specific information about an offender managed under the Multi-Agency Public Protection Arrangements (MAPPA), for the purpose of protecting the public. Disclosure, for example to an employer, a new partner or the parent of a child in contact with an offender, may reduce access to potential victims, preventing further crimes occurring or resulting in the detection of such crimes. Disclosure may also result in social exclusion of the offender, however, aggravating risk by removing access to protective factors such as relationships or employment. ${ }^{1,2}$ There is anecdotal evidence that some offenders are preoccupied with a fear of disclosure, which leads to resentment and disengagement from services.

Multi-Agency Public Protection Agencies were introduced in 2001 under Sections 67 and 68 of the Criminal Justice and Court Services Act 2000 to facilitate the sharing of information among agencies to improve public protection (this Act has since been repealed, and related arrangements are now covered by Sections $325-327$ of the Criminal Justice Act 2003). Most, if not all, police forces in the UK use third-party disclosure, ${ }^{2}$ but no data are available on how often this is used. Police forces have reported that most commonly disclosures involve details of offences being communicated to school staff. $^{2}$ There is no evidence that directly addresses the question of whether the system of third-party disclosure used in the UK prevents crime overall, or whether it is effective in any particular subgroup of cases. The most recent MAPPA guidance $(2009)^{3}$ sets out four principles underpinning the use of disclosure: the disclosure should be lawful, proportionate, accurate and necessary. The potential risks to the offender should be considered, as should alternatives to disclosure. The person disclosing should check what the third party already knows, that they understand the confidential nature of the information disclosed, and that they know how to make use of the information. Only information that is necessary to reduce risk should be disclosed; often this will not include specific details of offences. For offenders managed at MAPPA level 2 or level 3 (where regular multi-agency discussion is considered necessary to manage risk), disclosure should be considered in all cases. Even in an emergency, any decision to disclose should be made on a multi-agency basis.

In the USA, community notification (public access to information about convicted sex offenders) has been mandatory since $1996 .{ }^{4}$ In a study of 15 states across the USA including more than 300000 sex offenders, the researchers concluded that community notification deterred new offenders overall but did not have any significant impact on the sexual re-offending rates of convicted sex offenders and did not reduce assaults by strangers on children. ${ }^{5}$ 
In England and Wales, the recently introduced Child Sex Offender Disclosure Scheme provides a system for members of the public to ask whether an individual they are concerned about has ever committed a child sex offence. When the scheme was piloted in four police areas over 12 months from September 2008, 585 enquiries were received and 21 disclosures of a previous child sex offence were made. ${ }^{6}$ Applicants reported being largely satisfied with the process, and police and offender managers thought the scheme formalised good practice. Registered sex offenders reported anxiety as a result of the scheme but said it had not changed their behaviour. There was no evidence of any serious breaches of confidentiality after disclosures had been made. A similar scheme is in place in Scotland. When this was piloted in Tayside from September 2009 to May 2010, 53 enquiries were received and 11 disclosures made. ${ }^{7}$ Applicants were largely satisfied with the process. No vigilante attacks were reported, and there was no increase in movement of registered sex offenders out of the area or decrease in compliance with notification requirements. In both the English and the Scottish pilot schemes, in addition to disclosures, enquiries triggered many referrals to children's services because of child protection concerns: it is likely the schemes enable actions to protect children that would not have been possible without the information provided by those making enquiries.

The legal landscape in this area is complex. The Data Protection Act 1998 governs the way in which personal data may be used. Article 8 of the European Convention on Human Rights confers the right to respect for private and family life, which can be infringed where 'necessary in a free and democratic society' and where this is proportionate. The Children Acts 1989 and 2004 give powers to make disclosures under child protection protocols. Section 140 of the Criminal Justice and Immigration Act 2008 inserted into the Criminal Justice Act 2003 a presumption that each MAPPA authority (comprising regional police, probation and prison services) should, where there is reason to believe that a child sex offender poses a risk of serious harm to a child and a disclosure is necessary to protect against such harm, disclose relevant information about the offender's previous child sex offence convictions. The police have a common law power and powers under the Crime and Disorder Act 1998 to share information to prevent and detect crime. Finally, individuals may come under a duty not to misuse information 'of a confidential nature' 'communicated in circumstances importing an obligation of confidence, 8

National Health Service (NHS) professionals should have regard to the NHS code of practice on confidentiality, ${ }^{9,10}$ and doctors should have regard to the General Medical Council's guidance in this area. ${ }^{11}$ These documents sanction disclosure of patient information without the patient's consent only in exceptional circumstances, most commonly where a failure to disclose could result in death or serious harm.

The law pertaining to disclosure decisions has been little tested in the courts. Three cases are of note. In the first, ${ }^{12}$ a married couple, both of whom had been convicted of sexual offences against children, were asked by police to move their caravan from a caravan park in advance of a holiday when children were likely to visit. The couple refused, and the police showed the park owner news reports about the couple's offences. The owner then asked the couple to leave. The court found that the police had acted lawfully, as they had 'disclosed to the degree necessary to perform their public duties'. In the second case, ${ }^{13}$ it was established that the police have a positive 'duty to warn' potential victims where there is evidence that there is a 'real and immediate' risk to life. In the third case,${ }^{14}$ the estranged wife of an offender who had served a 14-year sentence for rape had been informed that he was to be released from prison. She did not want to be present at matrimonial proceedings when the offender might be there and asked the local public protection unit for assistance. A police constable responded by writing a letter to her solicitor disclosing that the offender had intimidated staff and inmates while in prison, which the wife then used at court. In obiter dicta, the judge remarked that it was clear that the detective constable had wrongly disclosed certain information'.

The aim of this study was to investigate how decisions about third-party disclosure are made at level 2 MAPP meetings in the 33 London police and probation areas, and to examine adherence to MAPPA guidance. Given the absence of research in this area, no hypotheses were made.

\section{Method}

\section{Participants and procedure}

We devised a questionnaire and obtained approval for the study from the London MAPPA Strategic Management Board.

Ten copies of the questionnaire with stamped addressed return envelopes were sent to the MAPPA administrator for each of the 33 London police and probation areas, including the City of London, before their July 2011 level 2 MAPP meeting. We asked the MAPPA administrator to give the questionnaires to regular attendees at their July meeting, and the MAPP meeting chair to encourage the attendees to complete and return the questionnaires. Most level 2 MAPP meetings in London are attended by senior professionals representing the police, probation, mental health (general adult and forensic) and substance misuse services, children's services, housing and youth offending teams. Where the questionnaires were not handed out in July due to administrative problems, administrators were asked to hand them out in August, September or October as necessary.

\section{Questionnaire and data analysis}

The questionnaire made clear that all answers were anonymous. Participants were asked which agency they represented at the meeting, how confident they were about third-party disclosure law and procedures (using a fourpoint Likert scale), and how many times in the past 12 months they had made a disclosure without getting the agreement of the offender or a MAPP meeting first. They were asked to choose, from a list of six options, all the methods they had seen used over the past year at level 2 MAPP meetings to make a decision when it had not been possible to reach a consensus on whether to make a 
disclosure; they were also given the option of indicating that they had never known a consensus not to be reached. Participants were then asked to choose, from a list of seven options, how they thought decisions should be made in this situation, marking 1 for their first choice and 2 for their second choice. First choices were given a score of three and second choices were scored one. If two equal preferences were indicated, these were each given a score of two. A mean was calculated for each option to indicate popularity.

Participants were then given five hypothetical scenarios that were based on cases the authors had seen discussed at level 2 MAPP meetings in London (Box 1) and asked which one of a choice of statements most closely fitted their view about it. Data were entered into SPSS version 19 for

\section{Box 1 Hypothetical scenarios}

\section{Domestic violence case}

A domestic violence offender is discussed at a MAPP meeting because he has a new partner. Do you believe it is generally good practice to make a disclosure to the partner?

Yes, always - she has a right to know

Yes, if there's a history of domestic violence in front of children and the new partner has children; no otherwise

Yes, if there is a history of domestic violence against more than one partner; no otherwise

Yes, if there is thought to be a risk of violence to the new partner or any children; no otherwise

Indecent exposure case

An indecent exposure offender has offended on six occasions against adult stranger female victims over a period of 20 years. He has no other convictions. Do you believe it is generally good practice to make a disclosure to a new partner?

Yes, always, because he has committed a sexual offence

Yes, because there has been more than one sexual offence and victim

Yes, if the new partner has children; no otherwise

Yes, if there is thought to be a sexual risk to the new partner or any children; no otherwise

\section{Child sex offences case}

It comes to the attention of the MAPP meeting that a child sex offender living in his own flat has regular social contact with two other such offenders. He is not on licence any more but is on the Register. He poses a moderately high risk to children known to him but has no previous history of networking with other sex offenders or offending with others.

These friendships probably increase risk: both he and his two friends should be told to stop contact and if they don't, a sexual offending prevention order should be sought

These friendships are equally likely to increase or decrease risk; it depends on the individual situation

These friendships probably decrease risk: they should be supported

\section{Rape case}

A rape offender is on licence at approved premises. He poses a high risk to women who are unknown to him. He is accepted on a 4-week college course providing an introduction to a range of trades (e.g. plumbing, carpentry). The course leader and other participants are all male, and the course is held in a warehouse near the college. The offender is aware that he is not allowed to work in domestic premises.

No disclosure is necessary at present

A partial disclosure should be made: the offender must inform the course leader that he has been in prison and currently sees probation

A full disclosure to the course leader of his convictions and victim type is necessary because of the risk he poses

A full disclosure to the course leader of his convictions and victim type is necessary because the college has a right to know

\section{Aggravated burglary case}

A man is released from prison after serving a sentence for an offence in which he broke into a house, tied up the woman there, shut her children in a separate room, and stole two laptops and $\mathrm{f} 200$ in cash. He returns home to live with his partner and their 5 -year-old twins. He takes responsibility for taking the twins to and from school, and sometimes brings other children home to play with the twins. The family have been assessed by social services; there are no concerns regarding either of the parents' risk to the twins.

No disclosure is necessary at present 
Windows for analysis. Given the relatively small sample size, we collapsed the agency categories 'social services' (children and families), 'housing' and 'youth offending' into a single category of 'local authority'; the two participants representing the prison service were included in the 'probation' category.

\section{Results}

Questionnaires were handed out at all 33 level 2 MAPP meetings, but there were less than ten regular attendees present at a small number of them. A total of 321 questionnaires were handed out. We received 196 completed questionnaires, giving a response rate of $61.1 \%$. The highest number of missing values was for the question about confidence in disclosure procedures $(n=11)$, followed by the question about the aggravated burglary scenario $(n=8)$.

\section{Participants' agencies}

In total, 33 responses (17\%) were from mental health (including substance misuse) service representatives, 48 responses (25\%) were from police representatives, 50 responses $(26 \%)$ were from probation representatives, and 65 responses (33\%) were from local authority representatives (social services (children and families), 26 (13\%); housing, 30 (15\%); youth offending, 9 (5\%)).

\section{Confidence in disclosure law and procedures}

Overall, most participants $(n=162 ; 84 \%)$ were fairly or completely confident about third-party disclosure law (Table 1). There was a significant difference between agencies, with the police being more confident than other agencies $\left(\chi^{2}=32.47\right.$, d.f. $\left.=6, P<0.01\right)$. There was a similar pattern in participants' understanding of disclosure procedures, with 153 participants (83\%) fairly or completely confident. Again, the police were significantly more confident than other agencies $\left(\chi^{2}=36.26\right.$, d.f. $\left.=6, P<0.01\right)$.

\section{Disclosure without MAPP meeting agreement}

A total of 120 participants (63\%) had not made a disclosure to a third party without the consent of the offender or the agreement of a MAPP meeting in the past 12 months. Forty-six participants (24\%) had made such a disclosure once or twice, 17 participants (9\%) 3-6 times, 7 participants (4\%) 7-12 times, and 2 participants (1\%) more than 12 times. Due to small cell counts (more than $10 \%$ of cells with an expected count below five), the latter three categories were collapsed into one category (three or more disclosures) for chi-squared testing. There was a significant difference between agencies, with 30 police participants $(64 \%)$ having made at least one disclosure without offender consent or MAPP meeting agreement in the past year, compared with 16 local authority participants (25\%), 19 probation participants $(40 \%)$ and 7 mental health participants $(21 \%)$ $\left(\chi^{2}=24.15\right.$, d.f. $\left.=6, P<0.01\right)$.

\section{Decision-making when a consensus cannot be reached}

Table 2 shows the results for two questions: first, "Very occasionally, MAPP meeting attendees disagree about whether a disclosure should be made to a third party, and a consensus cannot be reached. In your experience, if this happens, how are decisions made?'; and second, 'In your opinion, what do you think would be the best way to make the decision? Please mark 1 for your first choice and 2 for your second choice'.

A total of 109 participants $(55.9 \%)$ reported that in their experience it had always been possible to reach a consensus. Where there were sufficient data (fewer than $10 \%$ of cells with an expected count below five) for chisquared testing (one vote per person, MAPP meeting chair decides, always possible to reach a consensus), there were no significant differences by agency.

\section{Hypothetical scenarios}

In the domestic violence case and the indecent exposure case shown in Box 1, only the options 'Yes, if there is thought to be a risk of violence to the new partner or any children; no otherwise' (48\%) and 'Yes, if there is thought to be a sexual risk to the new partner or any children; no otherwise' (52\%), respectively, are in line with MAPPA guidance and relevant law providing that disclosure should be only for the purpose of public protection and should be proportionate. The first option in the domestic violence case and the indecent exposure case and the fourth option in the rape case are clearly contrary to this guidance: $44 \%, 31 \%$ and $12 \%$ of participants, respectively, selected these options. There was no significant association between choosing any of these options and confidence in the law relating to disclosure to third parties.

The most agreement was among participants in the child sex offences case, with $77 \%$ of participants believing that friendships between child sex offenders increase risk. The spread of responses to the other scenarios, especially to

\begin{tabular}{|lccccc|}
\hline Table 1 Confidence in disclosure law and procedures & & & & \\
& $\begin{array}{c}\text { Police } \\
(\%)\end{array}$ & $\begin{array}{c}\text { Probation } \\
n(\%)\end{array}$ & $\begin{array}{c}\text { Mental health } \\
n(\%)\end{array}$ & $\begin{array}{c}\text { Local authority } \\
n(\%)\end{array}$ & $\begin{array}{c}\text { Total } \\
n(\%)\end{array}$ \\
\hline $\begin{array}{l}\text { Understanding of the law }{ }^{\star \star} \\
\text { Completely }\end{array}$ & $34(71)$ & $14(29)$ & $7(21)$ & $18(29)$ & $73(38)$ \\
Fairly & $10(21)$ & $29(59)$ & $18(55)$ & $32(51)$ & $89(46)$ \\
A bit/not at all & $4(8)$ & $6(12)$ & $8(24)$ & $13(21)$ & $31(16)$ \\
\hline Understanding of the procedures* & $34(72)$ & $21(45)$ & $5(17)$ & $19(31)$ & $79(43)$ \\
Completely & $9(19)$ & $23(49)$ & $14(47)$ & $28(46)$ & $74(40)$ \\
Fairly & $4(9)$ & $3(6)$ & $11(37)$ & $14(23)$ & $32(17)$ \\
A bit/not at all & & & & & \\
\hline
\end{tabular}

${ }^{\star} P<0.05$, ${ }^{*} P P<0.01$. 


\begin{tabular}{|c|c|c|}
\hline & $\begin{array}{c}\text { Past decisions }{ }^{a} \\
n(\%)\end{array}$ & $\begin{array}{l}\text { Best way to } \\
\text { decide, }{ }^{b} n\end{array}$ \\
\hline Vote - one vote per agency & $16(8)$ & 0.57 \\
\hline Vote - one vote per person & $37(19)$ & 0.58 \\
\hline $\begin{array}{l}\text { The Multi-Agency Public } \\
\text { Protection (MAPP) chair decides }\end{array}$ & $50(26)$ & 0.85 \\
\hline $\begin{array}{l}\text { The agency with primary } \\
\text { statutory responsibility decides }\end{array}$ & $9(5)$ & 0.45 \\
\hline The police decide & $9(5)$ & 0.06 \\
\hline Probation decides & $2(1)$ & 0.02 \\
\hline $\begin{array}{l}\text { It has always been possible to } \\
\text { reach a consensus/keep } \\
\text { discussing until we reach a } \\
\text { consensus }\end{array}$ & $109(56)$ & 1.04 \\
\hline
\end{tabular}

a. 'Choose as many ways of deciding as you have seen used over the past year.' b. Mean score based on first choices scoring three points and second choices scoring one point.

the rape case, was marked, demonstrating diverse opinions about disclosure decisions among London level 2 MAPP meeting attendees. In the aggravated burglary case, a clear majority favoured no disclosure.

We used chi-squared analyses to determine whether there were differences in responses between agencies. After initial analysis, options were collapsed into fewer categories, so that fewer than $10 \%$ of cells had an expected count of less than five. Differences were found in two of the cases. In the indecent exposure case (second and third options collapsed), probation participants were significantly more likely to choose 'Yes, always, because he has committed a sexual offence', and police participants were significantly more likely to choose 'Yes, if there is thought to be a sexual risk to the new partner or any children; no otherwise', compared with the other groups $\left(\chi^{2}=18.68\right.$, d.f. $=6$, $P<0.01)$. In the rape case, mental health participants were significantly more likely to choose 'A full disclosure to the course leader of his convictions and victim type is necessary because of the risk he poses' and police participants were significantly more likely to choose 'No disclosure is necessary at present' compared with the other groups $\left(\chi^{2}=20.19\right.$, d.f. $\left.=9, P<0.05\right)$.

\section{Discussion}

\section{Strengths and limitations}

To our knowledge, this is the first study examining decisionmaking about disclosure to third parties at MAPP meetings. We had a high response rate from participants across the spectrum of level 2 MAPP meeting attendees. The hypothetical scenarios in the questionnaire were based on cases we have seen discussed at MAPP meetings, but they lacked much of the additional information often available to MAPP meeting attendees, and participants were given only limited options from which to choose rather than being free to seek further information and devise plans to suit particular circumstances, including plans to discuss voluntary or mandatory disclosure with the offender. The scenarios were deliberately chosen to reflect potentially uncomfortable situations; greater agreement may have been achieved if less challenging scenarios had been presented. Our conclusions are based only on the participants who responded and so a response bias is possible. Our findings may not be generalisable to areas outside London.

\section{Confidence}

It appears that level 2 MAPP meeting attendees in London, particularly police attendees, are generally confident about their knowledge of the law and procedures relevant to disclosure decisions. Given the divergent views expressed in the responses to the scenario questions in this survey, and the relatively high number of responses that were not in line with law and guidance in this area, some of this confidence may be misplaced.

\section{Decision-making}

Guidance for MAPPA states that for offenders classified as level 2 or level 3 (i.e. whose risk to others is such that regular multi-agency discussion is required), decisions to disclose should be made on a multi-agency basis 'even in emergency situations. ${ }^{3}$ In London, it appears that the police are the agency that most often makes disclosures without a level 2 offender's consent and without multiagency discussion, but more than $20 \%$ of participants from all agencies reported having done this at least once over the past 12 months.

The role of a MAPP meeting chair, according to MAPPA guidance, includes 'testing for consensus' and 'creating an agreed MAPPA risk management plan', ${ }^{3}$ but no further advice is given on how decisions should be made. A variety of methods appear to be used where a consensus cannot be reached on whether to make a disclosure. More than half of participants, however, reported that they had never experienced a consensus not being reached. Given the often widely divergent views held by MAPP meeting attendees, this raises the question of what is meant by a 'consensus' in this context. It may be that such decisions are not subject to the level of scrutiny described in the MAPPA guidance.

Only a small number of participants indicated that they had observed the agency with primary statutory responsibility for an offender decide whether a disclosure to a third party should be made when a consensus could not be reached, and only a small number highlighted this as one of their preferred ways for decisions to be made when this happened. A recent inspection of MAPPA recommended an increased focus on the identification of the lead agency for each offender and on the responsibility of this agency for coordinating and leading on risk management. ${ }^{15}$ In contrast to offenders with level 1 MAPPA, who are managed by a single agency, there is a risk with level 2 or level 3 offenders that responsibility for decisions can be diffused among MAPP meeting attendees, with no individual or agency accountable. This may reflect a misconception that a MAPP meeting has independent authority in its own right rather than being a forum for multi-agency collaboration that does not supersede lead agency responsibilities. Some of the language in the MAPPA guidance contributes to this 
misconception, saying, for example, that the 'collective decision of the MAPP meeting to disclose' is usually sufficient authority for a disclosure. ${ }^{3}$

\section{Basis for decisions}

The MAPPA guidance and UK law sanction disclosure without the consent of the offender where this is necessary for public protection and is proportionate. In the domestic violence and indecent exposure hypothetical scenarios in Box 1, one of the options has disclosure contingent on risk to others. Only approximately half of participants chose this option in each case. Three of the scenarios had a 'right to know' type option: in the domestic violence case, almost half of participants favoured disclosure to a new partner based on their perceived right to know their partner's history of domestic violence; in the indecent exposure case, around a third favoured disclosure simply because the offender had committed sexual offences; and in the rape case, $12 \%$ felt the college had a right to know details of the offender's history. The moral position indicated by these responses - that the interests of others (whether or not potential victims) have absolute priority over the interests of offenders in such circumstances (or that offenders forfeit any right to privacy when they commit sexual or violent offences) - is understandable. Currently, however, there is no such right to know in UK law.

Risk assessment is central to establishing that a disclosure is for the purpose of public protection and is proportionate to achieving this purpose. Knowledge of the evidence base on re-offending should inform risk assessment in individual cases. It would be reasonable to think that the new partner of a domestic violence offender is likely to be at significant risk from the offender. In contrast, the available evidence suggests that although offenders who repeatedly expose themselves to strangers pose a high risk of sexual re-offending, there is no evidence to suggest that these offenders are diverse in their offending patterns, and the risk of sexual violence to a partner or her child would usually be extremely low. ${ }^{16}$ In the rape case, it is unclear how a disclosure would protect potential victims. In the aggravated burglary case, the potential victims (children in general, where children were incidentally involved in an aggravated burglary in the past) are highly unlikely to be harmed. Any benefit of disclosing in these cases would need to be weighed against both possible harm to the offender and any possible increase in risk to others if the disclosure led to the termination of a protective relationship or removal of a work opportunity.

More than three-quarters of participants in the survey thought that friendships between child sex offenders 'probably increase' risk and should be stopped. The balance of evidence does not support this view. 'Emotional loneliness' (the lack of capacity to make friends and feel close to others) has been found to have a modest association with increased risk, ${ }^{17}$ and anecdotal evidence suggests that such friendships reduce risk by reducing social isolation. Having negative social influences (antisocial peers) has only a tentative relationship to the risk of re-offending in child sex offenders; ${ }^{18}$ when friendships with other convicted sex offenders were specifically investigated, no association with increased risk was found. ${ }^{19}$

\section{Implications}

There is a clear need for better understanding of the law and guidance relevant to third-party disclosure, and of the evidence regarding risk to others, that should underlie decisions on whether or not to make a disclosure. Our study raises concerns that attendees at level 2 MAPP meetings in London may not be adhering fully to MAPPA guidance. Given both the potential harm and the potential benefit caused by a decision to make a disclosure, it is important that those involved are suitably trained and that an adequate governance system is developed to monitor and improve decision-making. The current auditing of London MAPP meeting minutes for a record that disclosure has been considered in all cases appears to be ensuring this happens more often but is unlikely to have an impact on the quality of the decision making once the possibility of a disclosure has been raised.

After sentencing, it is rare for offenders to secure legal or other advocacy services in relation to their management. In addition to training and governance within and between MAPPA agencies, a system of advocacy provision for offenders subject to MAPPA may help protect the interests of everyone in ensuring that decision-making is transparent and decision makers can be held accountable.

Future research could compare our findings and practice in other areas. It would also be interesting to explore the utility of the questionnaire as a measure of change, administering it before and after training.

\section{Funding}

Stationery and postage were funded by Oxleas NHS Foundation Trust.

\section{Acknowledgements}

We thank Charles Hayward and Angus Cameron (London MAPPA Strategic Management Board) and Simon Creighton (Bhatt Murphy Solicitors) for their helpful comments on the design of the study and content of the questionnaire.

\section{About the authors}

Catherine Penny MRCPsych is a specialty registrar (ST6) in forensic psychiatry at Community Forensic Mental Health Team (Lambeth), South London and Maudsley NHS Foundation Trust and a visiting teacher at the Department of Forensic and Neurodevelopmental Science, Institute of Psychaitry, King's College London. Jackie Craissati PhD is a consultant clinical and forensic psychologist and the clinical director of the Forensic, Prisons and Challenging Behaviour Directorate of Oxleas NHS Foundation Trust.

\section{References}

1 Ward T, Stewart C. Criminogenic needs and human needs: a theoretical model. Psychol Crime Law 2003; 9: 125-43.

2 Cann J. Assessing the Extent of Discretionary Disclosure under the MultiAgency Public Protection Arrangements. Home Office, 2007.

3 National Offender Management Service Public Protection Team. MAPPA Guidance, Version 3.0. Ministry of Justice, 2009 (http://www.justice. gov.uk/offenders/public-protection-manual).

4 Megan's Law (1996). Available at: http://thomas.loc.gov/cgi-bin/query/ z?c104:H.R.2137.ENR: (see Section 1). 
5 Fitch K. Megan's Law: Does it Protect Children? NSPCC, 2006.

6 Kemshall H, Wood J. Child Sex Offender Review Public Disclosure Pilots: A Process Evaluation (2nd edn). Home Office, 2010.

7 Chan V, Homes A, Murray L, Treanor S. Evaluation of the Sex Offender Community Disclosure Pilot. Scottish Government Crime and Justice Research, 2010.

8 Coco v. AN Clark (Engineers) [1968] FSR 415.

9 Department of Health. Confidentiality: NHS Code of Practice. Department of Health, 2003.

10 Department of Health. Confidentiality: NHS Code of Practice Supplementary Guidance: Public Interest Disclosures. Department of Health, 2010.

11 General Medical Council. Confidentiality. GMC, 2009.

$12 R$ (on the application of Thorpe) v. Chief Constable of North Wales [1997] 4 All ER 691.

13 Osman v. United Kingdom (23452/94) [2000] 29 EHRR 245.
$14 R$ (on the application of Pewter) $v$. Metropolitan Police Commissioner [2010] unreported.

15 HMI Probation, HMI Constabulary. Thematic Inspection Report: Putting the Pieces Together. An Inspection of Multi-Agency Public Protection Arrangements. HMI Probation and HMI Constabulary, 2011.

16 Morin JW, Levenson JS. Exhibitionism: assessment and treatment In Sexual Deviance: Theory, Assessment and Treatment (eds DR Laws, WT O'Donohue): 76-107. Guilford Press, 2008.

17 Hanson RK, Harris AJR, Scott T-L, Helmus L. Assessing the Risk of Sexual Offenders on Community Supervision: The Dynamic Supervision Project (User Report 2007-05). Public Safety Canada, 2007.

18 Mann R, Hanson K, Thornton D. Assessing risk for sexual recidivism: some proposals on the nature of psychologically meaningful risk factors. Sex Abuse 2010; 20: 1-27.

19 Hanson K, Harris A. Dynamic Predictors of Sexual Recidivism. Department of the Solicitor General Canada, 1998. 